\title{
La convivencia desde los imaginarios sociales: Encuentros mediados por la complicidad y la amistad'
}

\author{
The Coexistence From the Social Imaginary: Meetings Mediated by Complicity and \\ Friendship ${ }^{2}$
}

\section{A convivencia a partir do imaginário social: Encontros influenciados por complicidade e amizade ${ }^{3}$}

Mauricio Orozco-Vallejo Universidad Católica de Manizales

Manizales, Colombia maorozco@ucm.edu.co

Recibido • Received • Recebido: 28 / 06 / 2018

Corregido • Revised - Revisado: 11 / 11 / 2019

Aceptado • Accepted • Aprovado: 12/ 02 / 2020

\footnotetext{
'El presente artículo de investigación es derivado de un proyecto denominado "La Convivencia: Una aproximación a los imaginarios sociales en los estudiantes del Instituto Humanista de Pereira", en calidad de trabajo de grado de maestría en educación, Universidad Católica de Manizales (2016-2017).

${ }^{2}$ This research article is derived from a project called "Coexistence: An approach to social imaginaries in students of the Humanist Institute of Pereira", as a work for the Master's degree in Education, Catholic University of Manizales (2016-2017).

${ }^{3}$ Este artigo de pesquisa é derivado de um projeto chamado "Coexistência: uma abordagem para imaginários sociais de estudantes do Instituto Humanista de Pereira", trabalhando como mestrandos em educação, Universidade Católica de Manizales (2016-2017).
} 
http://doi.org/10.15359/ree.24-2.5

ROR: https://ror.org/01t466c14 Universidad Nacional, Costa Rica

http://www.una.ac.cr/educare

educare@una.cr

Resumen: El presente artículo de investigación abordó la convivencia desde el encuentro con el otro ser, vislumbrado desde la teoría de los imaginarios sociales. La pretensión del trabajo radicó en la comprensión de los imaginarios sociales relacionados con la convivencia de estudiantes del Instituto Humanista de Pereira Risaralda (Colombia); para tal fin, se utilizó el enfoque y diseño de la complementariedad (Murcia y Jaramillo, 2008), que priorizó la etnografía reflexiva para el acercamiento a la realidad social de la escuela; seguidamente se llevó a cabo el trabajo de campo en profundidad que incluyó entrevistas, cartografías, grupos focales, categorizados con ayuda de la teoría fundada; la interpretación se logró desde la triangulación de la información. En los resultados se evidencia el aula de clase como un tiempo y espacio para expresar lo que se es y para sentir reconocimiento, acogida y ser parte del grupo social al que se pertenece; además de manera práctica e inusual se reconoce la amistad y la complicidad como expresiones latentes de imaginarios que disputan su naturalización, y otros que la resisten y la proyectan como posibilidad de socialización con el otro ser en la escuela.

Palabras claves: Convivencia; encuentro; amistad; imaginarios sociales.

Abstract: This research article addressed the coexistence from the encounter with the other, considered from the theory of social imaginaries. The paper aimed to understand social imaginaries related to the coexistence of students from the Humanist Institute of Pereira Risaralda (Colombia). For this purpose, the approach and design of complementarity were implemented (Murcia \& Jaramillo, 2008), prioritizing the reflexive ethnography for the approach to the social reality of the school. Then, the field work was carried out in depth with interviews, cartographies, and focus groups, categorized with the help of the well-founded theory. The interpretation was achieved through the triangulation of information. The results show the classroom as a time and space to express what a human being is and to experience recognition and acceptance, and to be part of the social group people belong to. Moreover, practically and unusually, friendship and complicity are recognized as latent expressions of imaginaries that dispute their naturalization and other imaginaries that resist it and project it as a possibility of socialization with the other in the school.

Keywords: Coexistence; encounter; friendship; social imaginaries.

Resumo: $O$ presente artigo de pesquisa abordou a convivencia a partir do encontro com $O$ outro, vislumbrado a partir da teoria dos imaginários sociais. A pretensão do trabalho baseouse na compreensão dos imaginários sociais relacionados à convivência de alunos do Instituto Humanista de Pereira Risaralda (Colômbia); para tanto, utilizou-se a abordagem e delineamento da complementaridade (Murcia e Jaramillo, 2008), que priorizaram a etnografia reflexiva para a abordagem da realidade social da escola; Posteriormente, o trabalho de campo foi realizado com entrevistas em profundidade, cartografias e grupos focais, categorizados com a ajuda da teoria fundamentada; a interpretação foi obtida a partir da triangulação da informação. Os resultados mostram a sala de aula como um tempo e espaço para expressar-se sobre si mesmo, sentir-se reconhecido, acolhido e parte do grupo social ao qual pertence; Além disso, de maneira prática e incomum, a amizade e a cumplicidade são reconhecidas como expressões latentes do imaginário que contestam sua naturalização e outras que resistem a ela e a projetam como uma possibilidade de socialização com o outro na escola.

Palavras-chave: Coexistência; encontro; amizade; imaginários sociais. 
http://doi.org/10.15359/ree.24-2.5 ROR: https://ror.org/01t466c14 Universidad Nacional, Costa Rica http://www.una.ac.cr/educare educare@una.cr

En todo aprender humano se da la experiencia de un encuentro. Se aprende, sobre todo, más que un contenido, una relación

(Bárcena y Mèlich, 2014, p. 187)

\section{Introducción}

El ser humano por naturaleza se ve en la necesidad de acercarse a otros seres con características tal vez similares, pero con pensamientos diversos y algunas particularidades que lo presentan como un ser único; ahí, en esa proximidad con los otros sujetos surge la convivencia, en ella se hace uso de la palabra y el lenguaje como puente para llegar a la otra persona, para dar a conocer emociones, sentimientos, ideas, saberes o conocimientos y para ser usada en beneficio de la colectividad. Desde la perspectiva de Gadamer (1996, citado por Aguilar, 2003, p. 12), la convivencia "es lo que nos eleva por encima del mundo animal, justamente por medio del lenguaje como capacidad de comunicación".

El presente artículo busca mostrar algunas de las categorías emergentes del proyecto referido (complicidad y amistad), en tanto ellas se proyectan como posibilidad de configurar, a partir de las significaciones imaginarias nuevas formas de relacionamiento en los escenarios educativos. Para Castoriadis (1997, p. 198) "las significaciones imaginarias sociales crean un mundo propio para la sociedad considerada, en realidad ellas son ese mundo; y forman la psique de los individuos". Por tanto, este texto da cuenta de esas significaciones relatadas y practicadas por los actores y actoras sociales quienes expresan y se expresan a través de sus palabras, acciones y gestos en la convivencia de sus instituciones educativas.

El lenguaje funge aquí como un elemento articulador entre el mundo interior de un sujeto y el mundo exterior; dicho de otro modo, entre su propia manera de ser y de hacer y lo que la relación con la cultura, con el símbolo le provee. Para Castoriadis (2013, p. 187)“nos encontramos primero, está claro, con lo simbólico en el lenguaje. Pero lo encontramos igualmente, en otro grado y en otra manera, en la instituciones".

Partiendo de esta premisa, en el panorama actual en el contexto colombiano de los procesos de Paz que se han venido gestando y de los acuerdos que se han logrado, se visibilizan otras maneras de comunicarnos y encontrarnos con los otros seres, de resolver las diferencias por medio de acciones dialógicas que permiten superar la tradición violenta ${ }^{4}$ que se ha instaurado y convivir con los demás individuos desde otras formas, donde la escuela resulta parte esencial en este proceso.

\footnotetext{
${ }^{4}$ En la apuesta de Emmanuel Levinas por una filosofía primera de la alteridad y de la ética, la violencia surge en la reducción del Otro al Mismo, origen de cualquier totalitarismo ontológico, político, social. Expone Levinas $(1977$, p. 20) que "la violencia no se produce tanto en la irracionalidad individual que se opone al discurso universal razonable, sino precisamente en la negación del ente concreto e individual por parte de este discurso".
} 
http://doi.org/10.15359/ree.24-2.5

ROR: https://ror.org/01t466c14 Universidad Nacional, Costa Rica

http://www.una.ac.cr/educare

educare@una.cr

No obstante, convivir no es sinónimo solamente de estar junto a otros u otras, de compartir un lugar, espacio o territorio, de estar en medio, o entre o implicado con las demás personas. En la racionalidad planteada en este artículo, el convivir está ligado y puesto en evidencia por la tensión latente y permanente de los imaginarios sociales, esas formas y modos que nos definen de una y no de otra manera, que nos hacen tomar partido en el mundo y contra el mundo. Aquí, se hace oportuno destacar que los imaginarios sociales se configuran desde tres niveles planteados por el filósofo Castoriadis $(1983,1997)$ y retomados en sus análisis por Murcia $(2012$, en cita a Castoriadis, 1983, p. 56), quien expone:

Los imaginarios presentan diferentes niveles de concreción: unos son radicales en tanto origen y raíz de algo, otros son instituyentes toda vez que se constituyen en motores de la institución de lo social, y otros son instituidos, pues devienen del reconocimiento y posicionamiento social. El imaginario radical-social instituyente no crea imágenes, aunque sí símbolos y formas, significaciones e instituciones, las dos siempre solidarias; es, en realidad, promulgación de lo que será, y en tal sentido es referente y forma referente, es constitución de lo nuevo, de lo no representable pero factible de ser organizado.

Desde esta perspectiva, se reconoce que en la escuela hay imaginarios institucionalizados relacionados con la violencia, el maltrato y el bullying; sin embargo, el interés investigativo de este trabajo se centró en la búsqueda y la atenta escucha por los imaginarios sociales instituyentes que configuran un mundo de relaciones dentro de la convivencia y que están generando impacto no solo en el medio educativo, sino en el personal, familiar y social.

En este sentido, una de las maneras en que se aproximó el trabajo a las voces del estudiantado fue asumiendo la teoría de los imaginarios sociales ${ }^{5}$, pues se asumió que es desde ellos desde donde las personas y las sociedades organizan sus mundos y dan sentido a lo común y a lo no común del mundo. Los imaginarios sociales se muestran y se realizan a través de la dimensión simbólica, cuya base dota de sentidos y de significados la vida social de las personas, ello expresado tanto en las prácticas sociales como en los discursos.

Castoriadis (1997, p. 133) sostiene que "es porque hay imaginación radical e imaginario instituyente que hay para nosotros 'realidad' y tal realidad". Podría decirse transponiendo esta

\footnotetext{
${ }^{5}$ En la teoría de los imaginarios sociales considerada por Castoriadis (1989) y contextualizada en el escenario educativo y pedagógico por Murcia (2012), se asume que los imaginarios son creencias y convicciones de las personas sobre formas de ser y de hacer, de decir y de representar una realidad social. En este sentido, los imaginarios sociales se constituyen a partir de dos dimensiones, la primera, la dimensión instituida, responsable de establecer los acuerdos, los pactos o las normas sobre lo que es el sujeto y la sociedad; la segunda, la dimensión radical/ instituyente, que expresa la total particularidad y singularidad del sujeto que encuentra en otros, condiciones de posibilidad para ser y proyectar aquello que aparece tan solo como anhelo y por venir.
} 
http://doi.org/10.15359/ree.24-2.5

ROR: https://ror.org/01t466c14 Universidad Nacional, Costa Rica http://www.una.ac.cr/educare

afirmación a la comprensión de la convivencia, que es porque hay imaginario instituyente hay para nosotros cierto tipo de prácticas y discurso alrededor de convivir con los otros sujetos y son ellos los que trazan nuestra acciones e interacciones en la vida cotidiana con las demás personas y con el mundo.

Justamente, es en la relación con el otro ser en donde se constituyen los procesos de subjetividad y dan paso a la intersubjetividad, esto coincide con lo expresado por Freire (1985, p. 113) al reconocer que "El hecho de conocer supone una situación dialéctica: no estrictamente un 'Yo pienso', sino un 'Nosotros pensamos'. No es el 'Yo pienso' el que constituye al 'Nosotros pensamos', sino más bien el 'Nosotros pensamos' lo que me posibilita pensar". El tener presente que no se está solo o sola, sino que hay otros seres que se encuentran alrededor, permite pensar en ellos, en cómo se convive, en cómo se comparte y en cómo se siente la vida en colectividad, en el "entre nos" que permite construir y consolidar la educación de manera social.

De ahí que la "buena convivencia" parte de acuerdos, del diálogo, del compromiso y de la responsabilidad de todas las personas actoras que se enmarcan en el grupo social, por ello Bárcena y Mèlich, (2014, p. 35) explicitan que "No es posible una educación que no tenga como punto de referencia el recuerdo y, simultáneamente, el compromiso por asentar la construcción de la sociedad en una ... cultura de la memoria". La educación y la convivencia están íntimamente ligadas, de tal manera que, entre ambas construyen, forman e impactan los entornos, van más allá de las fronteras de la escuela, permeando cada pensar y actuar del sujeto en colectividad.

Algunos estudios han abordado la convivencia desde múltiples perspectivas, entre las cuales se pueden asumir: convivir se aprende en las relaciones con los otros seres (Barquero, 2014), o sea, es un campo de acción e interacción entre subjetividades (Méndez y Mesa, 2015), un lugar donde la voz del estudiantado se expresa (Perales et al., 2013), una forma de prevenir la violencia (Fuentes, 2012), un lugar de comunicación (Duarte, 2005) o de gestión del conocimiento (Sandoval, 2014) en la búsqueda hacia la promoción de ambientes de aprendizaje (Rodríguez y González, 2015), incluso, se plantea la tensión entre multiculturalidad e interculturalidad (Leiva, 2010) o el convivir desde la mirada reglada y normalizada (Ochoa y Diez-Martínez, 2013) como campos de poder y de discusión sobre la propia naturaleza de la convivencia, también como un lugar de encuentro cara a cara con los otros individuos en la escuela Gijón y Puig (2010), o la convivencia desplegada en las voces de niños y niñas en educación secundaria (García-Pujadas et al., 2013), si se quiere, la escuela como punto de encuentro con otros sujetos y consigo (Dávalos, 2002), una pedagogía del encuentro que parta de la relación cuerpo-alteridad en la escuela (Jaramillo Ocampo y Murcia Peña, 2014) para que no se hable solamente del otro ser, sino que se hable con el otro ser (Jaramillo Ocampo y Orozco Vallejo, 2015). 
http://doi.org/10.15359/ree.24-2.5

ROR: https://ror.org/01t466c14 Universidad Nacional, Costa Rica

http://www.una.ac.cr/educare

educare@una.cr

\section{Materiales y métodos}

Al partir de la realidad social, se hizo un reconocimiento y comprensión de aquellos imaginarios instituyentes, poco visibilizados que han transitado alrededor de la convivencia, desde el encuentro, la amistad, el compañerismo, la otredad y la alteridad; para tal fin, se empleó el enfoque y diseño desde la complementariedad propuesto por Murcia y Jaramillo (2008), enmarcado dentro de los enfoques cualitativos y emergentes, a partir del cual se prioriza la complejidad de las relaciones sociales, recurriendo a diversas perspectivas teóricas y metodológicas que permitieron llegar a nuevas comprensiones de la convivencia desde las voces de todos los actores sociales.

Lo anterior, detectado por medio de observaciones participantes y registradas en notas de campo, dio paso a la revisión documental de antecedentes relacionados con la convivencia; así, se elaboraron unas fichas que, a posteriori, llevaron a una matriz que permitió sintetizar de cada investigación internacional, nacional y regional los datos de identificación y definición de categorías, identificación y definición de supuestos epistemológicos que respaldan la investigación, identificación de enfoques teóricos, diseño metodológico, principales hallazgos empíricos, principales hallazgos teóricos, y análisis del sujeto investigador lector. Al cruzar los antecedentes, se encontraron seis tendencias enmarcadas dentro de la categoría convivencia que fueron: Aprender a convivir, comunicación, violencia, conflicto vs sin conflicto, clima escolar y cultura escolar.

Para responder a la pretensión central del trabajo, cuyo propósito era comprender los imaginarios sociales alrededor de la convivencia en estudiantes del Instituto Humanista de Pereira, se acudió al enfoque y diseño complementario desarrollado por Murcia y Jaramillo (2008) para aproximarse a las realidades sociales y dar la palabra al otro ser. Si bien, en el principio de la complementariedad se hace menester tomar los aportes de múltiples corrientes y enfoques, también es pertinente reconocer:

- La importancia de poder construir teoría a partir de la comparación constante, propuesta por la teoría fundada.

- La necesidad de reconocer los rasgos culturales y poder reflexionar sobre ellos a partir de la propuesta de la etnografía reflexiva (Murcia y Jaramillo, 2008, p. 92).

En esta perspectiva se tomó como base la etnografía reflexiva, vista como la "descripción, interpretación y comprensión de fenómenos socioculturales y humanos" (Murcia y Jaramillo, 2008, p. 93). Mientras que, la teoría fundada estuvo presente para la categorización de datos cualitativos desde la categorización simple, axial y selectiva, en el procesamiento y análisis de la información. 
El diseño y enfoque estuvo trazado por tres momentos que son la pre-configuración, la configuración y la re-configuración. En la pre-configuración, se realizó un acercamiento a la realidad desde las observaciones registradas en los diarios de campo a partir de las cuales se construyó un esquema de inteligibilidad relacionado con las prácticas educativas y sociales que tomaban vida en los escenarios educativos, privilegiando la perspectiva inductiva o realidad contextual; a la vez y paralelamente, se dio paso a una revisión documental de antecedentes.

Seguidamente, en el momento de la configuración, se llevó a cabo el trabajo de campo en profundidad basado en los esquemas de inteligibilidad que previamente se habían elaborado producto de las observaciones, se aplicaron ocho entrevistas, doce cartografías y doce grupos focales a estudiantes de grado 11 a y 11 b, cuyas edades oscilaban entre los 16 y 25 años del Instituto Humanista de Pereira; además, aquí se tuvo presente el procesamiento de la información mediante la saturación de esta, a través de la categorización simple, axial y selectiva, lo cual permitió visibilizar recurrencias, relevancias, opacidades y categorías emergentes que en el siguiente momento serían analizadas y contrastadas.

Finalmente, se transitó por el momento de la re-configuración, donde se elaboró la triangulación o análisis de la información, teniendo presente la consolidación de la teoría sustantiva brindada por parte de las personas actoras sociales, la teoría formal constituida por los aportes tomados de los diferentes estudios base de la investigación, sumado a la interpretación y comprensión del sujeto investigador sobre las observaciones de los grupos estudiados.

Criterios: Es preciso comentar que este trasegar educativo se llevó a cabo en el Instituto Humanista de Pereira en jornada sabatina. La población en la cual se apreció el proceso eran perteneciente a grado $11 \mathrm{a}$ y $11 \mathrm{~b}$, por lo tanto las edades de estudiantes oscilaban entre los 16 y 25 años. Cabe resaltar que la mayoría de estudiantes eran repitentes y una parte desertora de la jornada regular. Los actores sociales participantes eran 34 estudiantes y 2 docentes; de este grupo, 8 se entrevistaron y con el resto se elaboraron los grupos focales y las cartografías. El proceso se realizó allí porque era el escenario y contexto de práctica pedagógica.

Algunos especialistas que guiaron este proceso investigativo fueron: Foucault (2002) con poder en la escuela, Skliar (2008) con el cuidado del frágil, Derrida (1998) desde el encuentro y la amistad, ello en diálogo con algunas teorías de la educación en Bárcena y Mèlich (2014) y Freire (1985), abordados desde la racionalidad de la teoría de los imaginarios sociales en Castoriadis $(1983,1997,2013)$ y Murcia $(2011,2012)$.

\section{Resultados}

El procesamiento de la información y su respectivo análisis dio como resultado un esquema que plantea como eje central la convivencia desde el encuentro con el otro ser, a partir de él se desprenden las siguientes categorías: Poder en la escuela, cuidado del frágil y encuentro, 
http://doi.org/10.15359/ree.24-2.5

ROR: https://ror.org/01t466c14 Universidad Nacional, Costa Rica

http://www.una.ac.cr/educare

educare@una.cr

cada una de ellas despliega sus respectivas subcategorías; en este artículo desarrollaremos la categoría encuentro con sus respectivas subcategorías. A continuación, se presenta el esquema de acuerdo social que emergió (Figura 1):

Figura 1: Esquema de acuerdo social. La convivencia: Encuentros mediados por la complicidad y la amistad

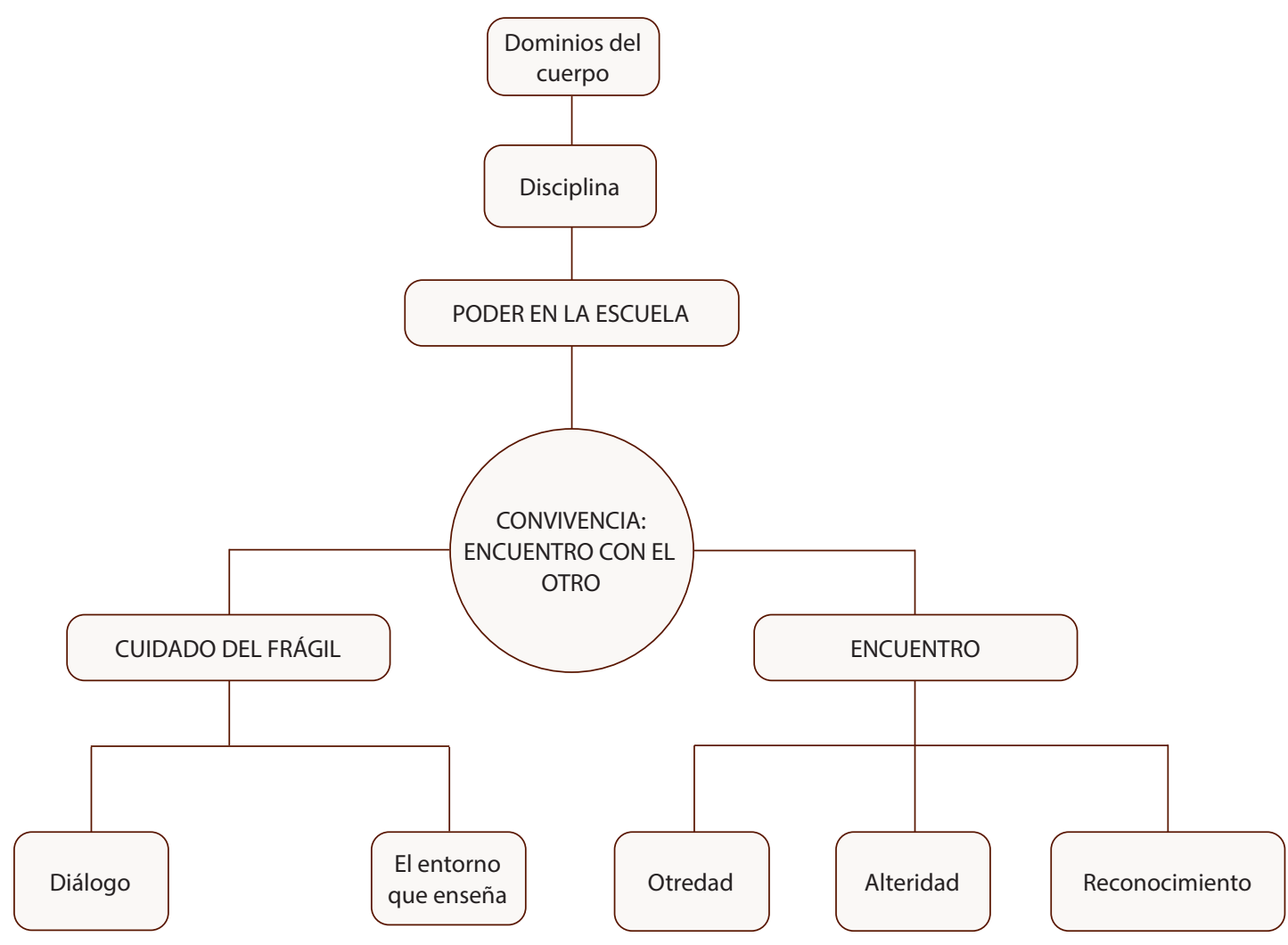

Nota: Elaboración propia.

Las emergencias desentrañadas desde los sentires y prácticas visibilizadas en el trabajo de campo se muestran en tres categorías: Poder en la escuela, cuidado del ser frágil y encuentro, con sus respectivas subcategorías que de ellas se derivan. A partir de ellas, se visibiliza en el estudiantado el reconocimiento y la importancia de la autoridad y la disciplina en la escuela, el personal docente es la figura representativa de las mismas; el cuidado del ser frágil se encontró priorizado desde la responsabilidad y la añoranza de ser escuchados o escuchadas, aspecto que en la escuela no es posible por múltiples factores, tales como el entorno y el contexto en el que se 
está inmerso y el encuentro se mostró desde el reconocimiento de la amistad en el otro individuo por medio del acercamiento y la complicidad. Lo evidenciado lleva a pensar en la necesidad de dar continuidad a los procesos de convivencia pacífica, donde se abarque el cuidado del ser frágil, el respeto, el reconocimiento, la amistad y la alteridad, pensando en la escuela como posibilidad de encontrarnos con el Otro ser y reconocerlo desde su heterogeneidad.

Para efectos del presente artículo, se expondrán los resultados de la macro categoría convivencia a partir del encuentro, la cual, agrupa tres subcategorías relevantes: Otredad, alteridad y reconocimiento. Desde estas formas de relacionamiento, surgen las prácticas y los discursos de convivencia en la escuela con respecto al encuentro que lo proyectan como lugar de amistad y de complicidad.

\section{Encuentros y desencuentros con el otro ser}

Justamente, para comprender la experiencia del aprender en los encuentros, debe partirse de una educación diferente que en Freire (1985) es una educación humanista que antepone la voz, la cultura y los saberes a las técnicas, los automatismos y las hegemonías en tiempos de desesperada "deshumanización". Por ello se hace un llamado a los encuentros, a las relaciones de acogida y hospitalidad, eso que en términos de Derrida (1998, citado en Skliar, 2008, p. 89) pretenden:

Acoger al otro en su lengua es tener en cuenta naturalmente su idioma, no pedirle que renuncie a su lengua y a todo lo que ésta encarna, es decir, unas normas, una cultura (lo que se denomina una cultura), unas costumbres, etc. La lengua es un cuerpo, no se le puede pedir que renuncie a eso ... Se trata de una tradición, de una memoria, de nombres propios.

Acoger en esta perspectiva es tratar al otro ser con nombre propio, es sacarlo del anonimato de la colectividad, es responder por su propio rostro que me llama y me clama, que me exige y me demanda aún en su más profundo silencio a una enseñanza que asuma el riesgo de la alteridad, de reconocerlo, cuidarlo y acogerlo; de esta manera, la alteridad es una respuesta responsable que da cabida al surgimiento de la amistad, en términos de Derrida (1998) "supone a la vez amor y respeto. Y debe ser igual y reciproca: amor reciproco, igual respeto" (p. 283).

Un afecto que se traduce en las prácticas de convivencia en la escuela como formas de atender la vulnerabilidad de la otro persona, como maneras de dar cuenta de la existencia del otro ser, un gesto que poco a poco hace que docente y estudiante transiten hacia la amistad, esa que implica que "el amigo es el próximo, y la amistad crece con la presencia, con la alocución en un mismo lugar. Esa es su verdad, su esencia, su modo de existencia" (Derrida, 1998, p. 323). La amistad sugiere ser fortalecida para existir, a la vez que requiere de respeto, de recibir y de dar; pues en Montaigne (s. f., citado por Derrida, 1998, p. 261) "aquel que da es aquel que recibe, nos dice 'De la amistad'. No da así más que con la condición de no tener lo que da”. 
http://doi.org/10.15359/ree.24-2.5

ROR: https://ror.org/01t466c14 Universidad Nacional, Costa Rica

http://www.una.ac.cr/educare

educare@una.cr

En sentido común, Eudamidas (s. f., citado por Derrida, 1998, p. 262) tiene una perspectiva de la amistad denominada "perfecta amistad" para lo cual establece "cada uno 'se entrega tan por entero' al amigo que no le queda nada para compartir, para repartir con otros' ". La amistad es pues un vínculo tan intrínsecamente ligado, que se fortalece con el pasar de los tiempos, se fundamenta con las vivencias o complicidades, se manifiesta en los pequeños detalles y en el compromiso y lealtad a quien se considera como amigo o amiga.

La amistad necesita ser replanteada en algunos escenarios sociales, educativos y de encuentro intersubjetivo; para ello, se asume la necesidad de una pedagogía de la alteridad en la siguiente consideración:

Una pedagogía de la radical novedad es una pedagogía de la exterioridad y de la alteridad - una pedagogía que presta atención a lo que se coloca fuera de la lógica del sistema- $y$, por esta razón, para una pedagogía así la educación es un acontecimiento ético, porque es en el seno de la relación educativa donde el rostro del otro, por decirlo con Lévinas, irrumpe más allá de todo contrato de toda reciprocidad. (Bárcena y Mèlich, 2014, p. 22)

El rostro del otro ser es lo que aparece, lo que se revela, la manifestación del otro ser que nunca podrá ser atendido de manera completa, predecible ni idéntica (Levinas, 2009, 2015). Sugiere el filósofo de Kaunas:

El Otro permanece infinitamente trascendente, infinitamente extranjero, pero su rostro, en el que se produce su epifanía y que me llama, rompe con el mundo que puede sernos común y cuyas virtualidades se inscriben en nuestra naturaleza y que desarrollamos también por nuestra existencia (Levinas, 1977, p. 208).

El otro ser, el que se pone en frente demanda un tipo de respuesta, un modo de relación. Pero no es solo la respuesta que parte de la obligación, del deber, de la norma, del manual, sino que es un Ilamado que aparece en su rostro. Sí, el "rostro no es la cara. El rostro es la huella del otro" (Bárcena y Mèlich, 2014, p. 148). Queda, de cierta manera, un vacío al aire sobre el respeto que se tiene hacia la huella del otro ser, que, aunque a veces no está de cuerpo presente, ha dejado una huella indeleble de coexistencia y de encuentros en ese tránsito por la relación de alteridad, por la relación de amistad. El otro ser que se acerca tiene un rostro, que, aunque no se quiera reconocer, valorar y escuchar, está ahí, demandando la responsabilidad de ser congéneres, hermanos y prójimos ${ }^{6}$, habitantes de un mismo espacio; es un rostro que quizás no se ve, pero sí se escucha.

${ }^{6}$ El prójimo es el nombre de un texto de Cohen (2004), donde se muestra el amor de Dios y el amor del prójimo no solo como mandato divino hacia el semejante, ante todo al extranjero, al forastero. Sostiene Cohen (2004, p. 24) que el "amor al prójimo se convierte en amor al ser humano".

10 Yeny Alejandra Hernández-López, Diego-Armando Jaramillo-Ocampo y Mauricio Orozco-Vallejo

Los artículos de la Revista Electrónica Educare del Centro de Investigación y Docencia en Educación de la Universidad Nacional, Costa Rica, se comparten bajo términos de la Licencia Creative Commons: Reconocimiento, No Comercial, Sin Obra Derivada 3.0 Costa Rica. Las autorizaciones adicionales a las aquí delimitadas se pueden obtener en el correo: educare@una.cr 
http://doi.org/10.15359/ree.24-2.5

ROR: https://ror.org/01t466c14 Universidad Nacional, Costa Rica http://www.una.ac.cr/educare

educare@una.cr

El rostro del otro ser, con el cual me puedo encontrar, conversar y tal vez, sentir cerca o hacerle sentir parte del transitar de una grata amistad es lo más esquivo y misterioso, lo que angustia la propia existencia y lo que deja perpleja nuestras seguridades sobre lo que es y no es el otro ser. Sin embargo, su rostro desbarata el baúl de los prejuicios e invita a responder de otra forma que no se ciñe a los lugares comunes de relación. Esto coincide con lo expuesto por (Skliar, 2008, p. 85) cuando se refieren a la alteridad como "la posibilidad de encontrarse con el otro, de iniciar el camino de un diálogo en el que cada uno pueda sentirse portador de un fragmento valioso de eso que llamamos mundo de la vida".

En la convivencia, vista como el encuentro con el otro ser y los otros seres, en el día a día, en el diario compartir y darse al prójimo, en el recibir y acoger a semejantes que son como uno o una, es donde se dan necesariamente una serie de acercamientos no solo de sentires, sino de cuerpos, de amistades, de presencias; donde la compañía del otro ser es relevante, sin él (sin su figura así sea en el recuerdo) no se puede llevar a cabo una convivencia con sentido y pleno significado, en el cual las partes puedan dar a plenitud lo mejor de sí y presenciar vivencias que les permitan construir recuerdos y llamarse tal vez"amigos".

Es en el encuentro que se da, en ese compartir, en el cual se exterioriza la ayuda y colaboración entre pares, así es como se deja en evidencia en un apartado del diario de campo: "Ios estudiantes parecen disfrutar de las actividades y se ríen, se colaboran, se muestran receptivos a la clase". (Diario de campo N. 으).

En la amistad, se presentan algunas contradicciones que tienen injerencia en la vida de las personas; sin embargo, en las personas actoras sociales se evidencia que la amistad es superior a lo que les pueda incomodar, todo bajo la norma del respeto y como fuente de compañerismo y por qué no decirlo, de solidaridad. Es por tal motivo, que un actor social realiza la siguiente aclaración sobre sus compañeros:

Todos se relacionan bien porque nos respetamos, compartimos muchos momentos, de manera que nos entendemos y aprovechamos cada que venimos a estudiar no solo para aprender sino para compartir. (Entrevista número, E4)

Lo anterior va ligado a lo que Kant (s. f., citado por Derrida, 1998, p. 282) saca a relucir pues: "No hay amistad sin 'respeto del otro'". Es precisamente el respeto hacia el otro ser el que debe primar, una amistad en la cual se pueda llegar al otro individuo, hacerlo partícipe, encontrarse en un ambiente que permita fortalecer el compañerismo y reconocer en él sus capacidades y así, entre ambas personas, crecer como seres humanos.

Siguiendo en la línea del respeto en los encuentros que se dan entre pares, hay una anotación que se destaca en un diario de campo: 
http://doi.org/10.15359/ree.24-2.5

ROR: https://ror.org/01t466c14 Universidad Nacional, Costa Rica

http://www.una.ac.cr/educare

educare@una.cr

A las 8:45 aproximadamente llega el estudiante (E21) al aula de clases, el cual saluda de manera efusiva, gran sonrisa y aparente alegría a sus compañeros y docente; inmediatamente el estudiante (E22) con un movimiento de rostro y de manos le indica al estudiante (E21) que se haga a su lado. El estudiante (E21) toma su lugar al lado del estudiante (E22) y se saludan de mano de una manera particular; mientras los demás comienzan a molestarlos y a insinuarles que se extrañan, que no pueden vivir el uno sin el otro, a lo cual el estudiante (E21) dice "no me enreden aquí que nosotros somos amigos", "ojo con eso" "que comentarios tan mal intencionados", se sonríen y se hacen juntos. (Diario de campo N.o 10).

Así como se describe en el apartado anterior, se presentan con regularidad momentos en los cuales el estudiantado muestra un apego hacia algunos de sus compañeros, amistades que se forman con el pasar de los días, meses y años, que lleva a pensar en Eudamidas (s. f., citado por Derrida, 1998, p. 206) quien haciendo alusión a la amistad esclarece:

Pues [esta] amistad perfecta de la que hablo es indivisible; cada uno se entrega tan por entero al amigo que nada le queda para repartir con otros; al contrario, lamenta no ser doble o triple o cuádruple y no tener varias almas y voluntades para dedicarlas todas a esa persona. Las amistades vulgares se pueden repartir...

Lo dicho hasta aquí supone que, para que se dé la amistad en primera instancia se da paso al compartir, al reconocer, al encontrarse con los otros seres en un gesto de cercanía y proximidad, esto es, en una completa complicidad de cuerpos, de palabras y de miradas que hace que la relación de amistad sea más fuerte que los comentarios de los demás compañeros o compañeras.

De ahí que, al pasar la línea del respeto y llegar a otras acciones que pueden afectar la convivencia, se decide indagar sobre las actividades violentas que se generan en el colegio, a lo cual un actor social responde:

Ninguna profe, yo creo que acá se maneja un ambiente social, todos socializamos como compañeros, las apreciamos como profesoras, eh no, me parece que no se genera ningún tipo de violencia y no, igual cuando chanzamos así pesado, igual sabemos que es una chanza, pero mas no ofendemos y no agredimos algún compañero, me parece que nos respetamos. (E1)

De igual manera, los demás compañeros y compañeras expresan que en el aula de clases no se presentan actividades violentas porque no hay personas que cumplan con dichas características, o así lo dejan en evidencia dos personas actoras sociales al pensar en la posibilidad de estudiar con personas agresivas o violentas: 
http://doi.org/10.15359/ree.24-2.5

ROR: https://ror.org/01t466c14 Universidad Nacional, Costa Rica http://www.una.ac.cr/educare

Pues yo creo que personalmente no me dejaría, si a mí me hablan con humildad yo atiendo con humildad, si me hablan con agresión yo también a veces no puedo controlar mis impulsos también reaccionaria de la misma manera, yo no puedo decir ah es que yo me sentaría y hablaría, yo no soy así, si a mí alguien viene y me grita yo creo que yo le grito y también le metería su puño, entonces pero si a mí me hablan bien y me tratan bien, igual yo brindo de lo que me dan, de lo que me dan de eso yo brindo. (E1)

Yo me considero una persona muy calmada, y pues si alguien viniera acá a buscar pleito pues no normal tiene que molestare mucho para sacarme la rabia, de resto no. (E2)

Queda claro entonces que para una parte del grupo de estudiantes la manera en la cual se les trata o se refieren a ellos o ellas debe ser en buenos términos; de lo contrario, reaccionan de maneras no pacíficas, dejando de lado el respeto por el otro ser y devolviendo las "malas acciones" recibidas, lo cual nos inquieta a pensar sobre la importancia de hallar caminos que les permitan encontrarse en espacios en los cuales el respeto hacia el otro ser se pueda dar, independientemente de las circunstancias, pues si una persona actúa de manera violenta o agresiva al acercarse a mí, lo puedo hacer cambiar de parecer con una respuesta noble y con un trato diferente al cual él me está brindando.

Ahora bien, un tema que despierta interesante discusión pedagógica es con respecto a la manera de referirse a los compañeros o compañeras a través de apodos, burlas o comentarios indiscretos en el aula de clase, a lo cual las personas actoras sociales (estudiantes) dan su punto de vista:

Ah pues porque son profes piensan así, pero a veces se nos pasa la mano molestando, pero no mucho. (E1)

Creo que tienen razón, hay comentarios que a veces se pasan, pero es como que ellos ya están acostumbrados así, pero si es un poco incómodo, porque las malas palabras o palabras soeces a mí no me gustan y eso me incomoda o algunos comentarios, pero yo respeto el punto de vista de ellos, pero si me gustaría que eso cambiara. (E2)

Pues si pueden tener razón porque a veces si se descachan en comentarios o burlas, pero cuando se les pide que por favor se respeten o se siga en el trabajo, hacen caso o uno les dice que están molestando mucho y ya. (E3)

Eso sí es verdad, pero para nosotros es normal, es la forma como nos tratamos y pues casi todos nos reímos. (E4) 
http://doi.org/10.15359/ree.24-2.5

ROR: https://ror.org/01t466c14 Universidad Nacional, Costa Rica

http://www.una.ac.cr/educare

educare@una.cr

Se hace notorio que, para la mayor parte del estudiantado este tipo de trato es muy "normal", de hecho, hay palabras particulares con las cuales se refieren a sus semejantes, y no se presentan altercados o discusiones entre ellos; así se deja en evidencia en el siguiente relato:

Hay un grupo de niñas que se hacen juntas y tienen una forma de recochar muy particular y es haciendo quedar mal a las otras o eso es lo que se puede percibir, pues cuando la docente pregunta por los trabajos E5 dice que ella si los hizo muy juiciosa, que ella no es como E1 que es una "bruta", "irresponsable" y se ríe, a lo cual E1 contesta "ay mueca deje de ser envidiosa mija que mi trabajo está más completo que el suyo"; la mayoría de la clase se pasan haciendo comentarios de este tipo, los compañeros se ríen y la docente las mira y continua con la clase sin pronunciarles palabra o referirse a ella (¿será que es normal ese trato?), las chicas parecen llevársela bien pues se hacen juntas, pero hasta por un lapicero se hacen comentarios como páseme el lapicero zumbambica, o por qué coge mis cosas compre, dígale a su marido que le compre, la otra le responde que va dígale a ese novio gordo feo que tiene que le enseñe a respetar. A medida que la clase transcurre las palabras que ellas emplean para tratarse, junto con otra estudiante son: Chucha, petacona, sapa páseme el lápiz, preste el cuaderno, entre otras. (Diario de campo № 14)

En el momento en el cual se dialoga con las personas actoras sociales sobre el trato que se da entre estudiantes y las malas palabras que a veces toman vida en las conversaciones, salen a la luz diversos comentarios, entre los cuales algunos sujetos están de acuerdo y otros se encuentran en discrepancia con esas anotaciones:

Profe es que a veces a uno se le salen, no es que quiera hablar groseramente, simplemente la recocha se da y dice malas palabras, pero uno al momentico cae en cuenta y cambia de tema o si le llaman la atención, uno dice hay perdón, pero no se hace con mala intención, pues de ofender a los compañeros no. (E5)

Profe es como en todo, hay palabras que uno no está de acuerdo porque son groseras, pero yo a veces les digo dejen de ser groseras, boquisueltas o boquisucias, y demás que hay compañeros que no les agradan esas palabras, pero igual si las dicen es solo por un momento. (E3)

Si profe, por ejemplo, yo soy una de las que no está de acuerdo con que se usen palabras soeces, me parece que es falta de respeto, pero sé que algunos compañeros lo hacen por costumbre y porque ese es el ambiente que a diario viven. (E6)

Al profundizar en el tema de los apodos que a veces toman vida en las conversaciones que se dan entre estudiantes y la posibilidad de cambiar de trato, las personas actoras sociales se muestran sinceras y conscientes de la situación; sin embargo, consideran que ello no les afecta y es una costumbre que hace parte de su diario vivir, en sus voces se deja entrever que: 
http://doi.org/10.15359/ree.24-2.5

ROR: https://ror.org/01t466c14 Universidad Nacional, Costa Rica http://www.una.ac.cr/educare

Casi siempre seguimos la corriente y nos reímos y todo eso, pero nadie se enoja, es muy bueno porque compartimos y se vuelve normal, petacona présteme el borrador, otro dice este petacón que no trae las cosas me coge todo sin permiso, las de muecas y muelonas son (E1) y (E5) que, porque la una tiene ortodoncia y le han sacado muelas y la otra que, porque tiene muchos dientes, y así, todos nos reímos.

- Cuando se dicen de esta manera nos causa gracia a todos, sin excepción, o sea cuando se dicen "petacones"; porque también hay otros apodos que los pronuncian entre los que más participan en la recocha y dependiendo el apodo nos causa gracia, más que apodos son palabras de momento, las dicen como para que todos nos riamos, así como mueca, flacuchenta, fea, tabla, bueno, pero lo dicen en buen tono de voz, como jugando y ninguno de los que participan y de los que escuchamos y observamos se molesta por ello. (E2)

-(Risas) No profe eso es normal, no pasa nada malo, solo nos divertimos y la pasamos bien, a todos nos causa gracia, así nos decimos entre todos, más las mujeres porque hay más confianza. (E6)

¿No pueden relacionarse de otra manera que no sea por medio de los apodos?

- Si lo hacemos o lo podemos hacer, pero es que no lo vemos como apodos o si, es forma de tratarnos diferente y con cariño, por molestar, no por nada malo, nos acostumbramos y es bueno. (E2)

- Yo creo que sí, pero se han acostumbrado a tratarse de esa manera, pero a veces se llaman por el nombre, cuando se dicen diferente es porque están recochando, pero también se llaman normalmente por el nombre. (E4)

-Creo que sí, pero ya es normal que se digan esas cosas, es como una recocha medio pesada, yes muy normal. (E6)

-Pienso que, si se podría, pero creo que es difícil por la costumbre que ya se tiene y la amistad que hay entre algunos, que hasta fuera del colegio comparten y como que están de acuerdo con la forma en la cual se tratan. (E7)

-Profe, se le perdería la gracia a todo, pues de que más hablaríamos, noooo. Asíestamos bien porque nadie se enoja y todos nos reímos, además uno sabe a quién molestary de qué manera que no se vaya a enojar. (E5) 
http://doi.org/10.15359/ree.24-2.5

ROR: https://ror.org/01t466c14 Universidad Nacional, Costa Rica

http://www.una.ac.cr/educare

educare@una.cr

Claro es, entonces, que para las personas actoras sociales el encuentro con sus pares está mediado por chanzas o comentarios no mal intencionados, en sus apreciaciones tratan de disfrutar y compartir los diversos espacios escolares; aparentemente se autorregulan y saben hasta qué punto llegar con sus comentarios y charlas. No obstante, el lenguaje se convierte no solo en fuente de malos entendidos, sino en lugar común de nombrar y ser nombrado por la palabra del otro sujeto, en lo que Levinas reconoce del lenguaje "como presencia del rostro, no invita a la complicidad con el ser preferido... el lenguaje es justicia" (Levinas, 1977, p. 226).

\section{Otredad}

El otro ser es otro individuo que no soy yo, otro ser que se encuentra fuera de lo que soy y escapa a mis propios poderes y dominios; o mejor, un alter ego, otro ser distinto a mí que se mantiene distante y lejano, que no perturba, que no altera, que en su separación no me invita a nada, no me produce nada, otro que no me obliga ni me ata, que simplemente vive su propia existencia en un lugar seguro sin ninguna interpelación ni con-tacto. El otro ser está en otro lugar, puede ser aceptado o tolerado, máxime reconocido; en las voces del estudiantado, lo asemejan a la familia y lo que ella en su integralidad comprende; esto se hace evidente cuando un actor social al hablar de sus pares y lo que se les puede resaltar o reconocer:

Yo como le he dicho los siento como una familia, que somos amigos, a pesar de que no hable mucho con ellos pues yo los siento como si fueran de mi familia, los siento muy cercanos a mí, y pues cuando tengo tiempo pues hablo con ellos, charlo, recocho... (E2)

Muy probablemente este relato es consecuente con la fraternidad espiritual que se explicita en Derrida (1998) la cual contrariando a la amistad natural:

Puede no ser más que uno de los atributos que aprecio en el otro, uno entre otros en esas "amistades vulgares" que son por definición divisibles. Mientras que la fraternidad de alianza o de elección, de figura o de juramento, la conveniencia de convención, la fraternidad de covenant, se diría en inglés, la fraternidad de conveniencia espiritual es la esencia indivisible de la "amistad perfecta". (p. 263)

Las voces expresadas muestran cómo sus pares se convierten en familia, pasan de ser personas extrañas a ser cómplices, hay cercanía por medio de la recocha y de la palabra. Pese a ello, el otro ser se mantiene distante y sin ninguna proximidad, sin acogimiento por lo que es o por lo que ha sido, hay una relación sin responsabilidad, sin compromisos ni obligaciones, hay una amistad vulgar que no trasciende a una verdadera amistad espiritual.

En este sentido, expone Viveros y Vergara (2014, p. 65) un análisis de la obra de Levinas en la que plantea que, para el autor, "la otredad es un darse cuenta de la presencia de alguien 
http://doi.org/10.15359/ree.24-2.5

ROR: https://ror.org/01t466c14 Universidad Nacional, Costa Rica http://www.una.ac.cr/educare

que está en la misma conflictividad consigo mismo; sin embargo, no hay acercamiento, hay distancia; solo una mirada dirigida al enigma de la otredad; acontece la pregunta".

El otro ser se muestra esquivo como un alter que diferencia y distingue, otro ser asociado con una familia que se une por lazos que no se medían por la palabra ni por el encuentro, quizás, sea la afiliación al grupo, la identidad colectiva que nace de la "recocha", del desmán, pero no se asume el rostro que interpela con nombre propio y con una voz única.

Lo anterior muestra un imaginario social en el que se naturalizan las prácticas sociales y los tipos de relación; es decir, aunque se aprecie el compartir con los demás compañeros y compañeras, se conserva un matiz de lejanía y de indiferencia, se da por "normal" cierto tipo de comportamientos que lo que hacen es solidificar o estructurar la realidad común entre unas personas y otras. Castoriadis (2013, p. 199) afirma que "las 'relaciones sociales reales' de las que se trata son siempre instituidas, no porque lleven un revestimento jurídico... sino porque fueron planteadas como maneras de hacer universales, simbolizadas y sancionadas".

\section{Alteridad}

Con respecto a la alteridad, se presenta una contradicción entre Kant y Lévinas (en Bárcena y Mèlich, 2014), pues para el primero (Kant), el otro ser es un sujeto autónomo, con capacidad de razonar, pero para él, el otro ser carece de rostro; en contraste con lo anterior, el segundo autor (Lévinas) presenta la alteridad como "una relación con el otro, -el rostro-, la voz que viene de fuera, que habla en imperativo y que demanda una responsabilidad más allá de todo pacto y de todo contrato" (Bárcena y Mèlich, 2014, p. 136).

Dicho lo anterior, se hace menester tomar uno de los relatos de las voces de las personas actoras (docente), quien trata de explicar cómo se da el compartir y el reconocimiento entre estudiantes; para tal fin lo describe de la siguiente manera:

Mira, al principio ellos son muy serios y muy retraídos entre sí y a medida que pasa el tiempo ya se van cogiendo confiancita ya se piden el número de teléfono, se llaman para hacer tareítas, se encuentran en clase y esos son los encuentros que tienen, pero a medida que pasa el tiempo ya se encuentran para hacer la tarea en la casa del compañero, ya salen juntos, a la hora del almuerzo salen juntos, oye mira te traje esto de la casa; entonces ese compartir se hace más fuerte y ya luego se reúnen para hacer saliditas, un crecer diario, eso espacios hacen que se van fortaleciendo lazos de amistad, y yo los he visto cuando se gradúan y que inclusive salen unos como mejores amigos, como es un compartir diario yo creo que esos espacios hacen que vayan fortaleciendo lazos de amistad. (D1) 
http://doi.org/10.15359/ree.24-2.5

ROR: https://ror.org/01t466c14 Universidad Nacional, Costa Rica

http://www.una.ac.cr/educare

educare@una.cr

Así el otro ser no esté de cuerpo presente y se den las conversaciones por otros medios, hay un compartir de ese otro ser y sus necesidades, pues es evidente que se ayudan, se colaboran, se hacen cómplices de momentos y tal vez de la vida. Son amistades que se forman y se fortalecen sin un compromiso por escrito o formalismos, sino con el simple hecho de la responsabilidad hacia el otro individuo, por el hecho de sentir y ser consecuentes con sus principios o con sus ideales, esos que les llevan a cooperar y cohabitar el mundo propio con otros seres semejantes, que, aunque aparentan ser similares, traen consigo unas implicaciones que, no obstante, por medio del departir y el entrañable vínculo que se crea, se pueden sobrellevar. Así lo continúan afirmando las personas actoras sociales al proferir sobre la pregunta: ¿Cómo te sientes al relacionarte con tus compañeros o compañeras?

—Bien, porque socializamos y es diferente a estar solo. (E2)

—Bien, porque compartimos con los otros, escuchan nuestras opiniones. (E3)

-Yo siento felicidad, porque yo por la casa soy muy sola, casi no tengo amigos y uno viene acá y se entretiene, tiene amigos y recocha y pasa bueno y aprende, todo al mismo tiempo. (E5)

Todo esto parece afirmar a Bárcena y Mèlich (2014) cuando esclarecen, "Me hago cargo del otro, cuando lo acojo en mí, cuando le presto atención, cuando doy relevancia suficiente al otro, y a su historia, a su pasado" (p. 158). Y es frecuente que mucho estudiantado llega a la escuela con situaciones difíciles, tratando de olvidar o disipar sus problemas en las actividades escolares; pero también es cierto, que al encontrar compañeros o amigas que les acogen, les escuchan, les integran, su actitud hacia la vida y hacia lo que les rodea cambia favorablemente; por lo tanto, aplica en este caso "El hombre que tiene amigos ha de mostrarse amigo; Y amigo hay más unido que un hermano" (Proverbios 18:24 Reina - Valera).

Lo anterior muestra un imaginario social que comienza a tomar fuerza instituyente, en tanto el estudiantado comienza a socializar y a encontrarse con otras personas como posibilidad de realizar muchas aspiraciones que hasta ahora se encontraban tan solo en cada quien, lo que coincide con lo expuesto por Castoriadis (1997, p. 189) al sostener que "nosotros no encontramos jamás individuos psicosomáticos singulares en estado 'puro'; sólo encontramos individuos socializados", y, es en esa socialización en la que la alteridad del otro va fisurando lo naturalizado propio de las instituciones y de las relaciones.

\section{Reconocimiento}

El compartir con el otro ser, que es compañera, amigo y tal vez hermano o hermana, permite que se llegue al reconocimiento de él, de ella, de ellos, de ellas, de sus potencialidades y de lo que encierra como ser humano; así se forman vínculos estrechos, vínculos de amor y amistad, esa amistad que: 
Se la definió tan frecuentemente por la conveniencia (oikeiotes) que conviene a la familiaridad, como a la afinidad que emparenta. Y ya tenemos aquí la locura. Si insistimos en esta extraña atopia del amigo, es porque podría entrar en una irreductible tensión con el principio a la vez tópico y familiar, el principio de conveniencia, justamente, que define en otro lugar lo político, pero en su vínculo con el vínculo de amistad. (Derrida, 1998, p. 259)

Lo que muy probablemente lleva a reflexionar sobre el significado que una actora social plantea en su representación gráfica:

En mi dibujo trato de mostrar algunos momentos que compartimos en grupo, aunque los compañeros dicen que yo casi no comparto..., yo si comparto y los considero como mi familia, sino que yo soy tímida, pero yo me rio de lo que ellos dicen. (E6)

Aquí, cuando se reconoce la perspectiva individual, es sin lugar a dudas el momento indicado para establecer acuerdos y comprender lo que hay detrás de algunas situaciones y actitudes, y por qué no decirlo, cuáles son los imaginarios sobre la convivencia que aparentemente se esconden y son tan difíciles de descifrar. Son relatos como el anterior que llevan a pensar en Bárcena y Mèlich (2014), quienes sostienen en su propuesta pedagógica que "la relación con el otro no es una relación contractual o negociada, no es una relación de dominación ni de poder, sino de acogimiento" (p. 22).

Seguramente el significado de acoger y reconocer al otro sujeto no está plasmado teóricamente en el estudiantado, pero sí lo aplican a su manera en el diario vivir y compartir, pues así se deja en evidencia en el siguiente apartado de un diario de campo.

...los estudiantes se muestran atentos y cuando la docente les dice que pueden conformar los grupos una estudiante le dice a otra, "yo con usted" y la señala con la mano "venga pues pa aca mugre", a lo cual la otra le responde "venga usted pa aca petacona", "que va usted no puede vivir sin mi" y se ríen, los demás se ponen a trabajar de manera muy juiciosa y acuden a la profesora cuando tienen inquietudes o comentarios, hay un grupo que se ponen a dialogar a la vez que escriben en sus cuadernos. (Diario de campo N.016)

El reconocimiento del otro ser pasa por las relaciones y los lazos construidos en el tiempo, por los vínculos establecidos en los momentos de disfrute y en los de desasosiego, en no solo ponerse en los zapatos del otro individuo, sino un pararse al lado de quien sufre, estar ahí en medio de todo y de nada, amar al otro ser más que ser su amigo o amiga (Cohen, 2004) y cumplir no tanto el mandamiento moral sino el mandato ético “... amarás a tu prójimo como a ti mismo" (Levítico 19: 18 y Marcos 12: 31).

Lo anterior expone un imaginario radical con aspiraciones instituyentes en las que el reconocimiento propio anhela el reconocimiento del otro ser, del prójimo, del individuo extraño 
http://doi.org/10.15359/ree.24-2.5

ROR: https://ror.org/01t466c14 Universidad Nacional, Costa Rica

http://www.una.ac.cr/educare

educare@una.cr

y de la persona extranjera. En línea con esto, Castoriadis (2013, p. 238) sugiere que "cada uno se define, y es definido por los demás, en relación a un 'nosotros"', pero ese nosotros o nosotras estará ligado al universo simbólico en el que el otro ser pueda reconocerse y sentirse reconocido, así, son las prácticas sociales las que trazan las acciones y las interacciones desde las cuales se reconoce a la otra persona, se acoge, se rechaza o se ignora.

\section{Conclusiones}

De una manera práctica y tal vez poco inusual, el estudiantado reconoce la existencia y la amistad en el otro ser, algo que insta a confirmar lo que en palabras de Derrida (1998) se podría asumir dentro del vínculo de la amistad "hay que ayudar al amigo, no por ayudarle, porque tenga necesidad, o porque ese sería el principio o el fin de la amistad, sino para darle signos de amistad" (p. 341). Tales signos de amistad son muchas veces ignorados por quienes desconocen la realidad del aula, imaginarios de convivencia que fortalecen y sellan lazos de compromiso, gratitud y afecto, que se denotan en grupos totalmente heterogéneos y disímiles.

Las perspectivas que se exponen entre docentes y estudiantes con respecto a los encuentros en algunos casos se muestran discrepantes y bastantes disyuntivas, pues tal vez la manera en la cual se da la dinámica escolar entre estas personas actoras no es vivida con la misma intensidad y quizás la brecha generacional que hay hace que se analice la convivencia desde perspectivas diferentes.

Lo anterior, lleva a pensar sobre la importancia de hallar caminos que permitan el diálogo y el encuentro en espacios en los cuales sea prioridad el respeto hacia el otro sujeto, de manera que el imaginario social de "devolver lo que me hacen" se puede contrarrestar, pues se debe fortalecer el entramado social y encaminarnos hacia una cultura de paz, amistad, complicidad y hospitalidad.

La amistad y la complicidad en la convivencia desde los imaginarios sociales se ponen en tensión desde lo instituido y lo instituyente. Lo primero, tratando de regular, naturalizar y ensordecer las presencias, los rostros y las vidas de quienes conviven en la institución educativa; lo segundo, buscando quiebres, rupturas y fisuras a eso que se impone y se antepone en la vida del estudiantado, y lo hace, desde la socialización, el compartir y el encuentro mediante el juego, la palabra, el tiempo y el espacio.

Ahora bien, de manera práctica se reconoce la amistad en el otro ser, hay un encuentro y acercamiento de cuerpos, de sentires, de voces que muestran complicidad, esa que les permite llegar a la otra persona; sin embargo, las formas en las cuales las llevan a cabo son poco reconocidas y establecidas como la terminología cultural que emplean para hacer referencia a los otros seres o sus códigos verbales, que en algunas ocasiones son tomados como apodos, 
http://doi.org/10.15359/ree.24-2.5

ROR: https://ror.org/01t466c14 Universidad Nacional, Costa Rica http://www.una.ac.cr/educare

burlas o comentarios indiscretos, mientras que para ellos o ellas son formas de departir, de convivir y encontrarse; en otras palabras, chanzas divertidas y cariñosas. Hay que destacar que el reconocimiento por la otra persona, por su heterogeneidad, por su amistad y compañía es evidente, pues con frecuencia se presenta una preocupación por su bienestar y su presencia, que en estos casos trasciende las fronteras del aula.

Debe reconocerse, también, que, en las representaciones elaboradas por la mayoría de estudiantes, se muestra el aula de clases como un lugar de encuentros, de manera particular su atención se centró en dibujar o representar los salones de clases y no otros espacios en los cuales pueden compartir, acoger y reconocer al otro ser; evidenciando así la importancia de estar cerca, de sentirle, de hacerle partícipe de momentos, de lugares, de la vida.

Así mismo, debe propenderse por llevar al estudiantado a generar espacios de colectivización en los cuales se permita reconocer al otro ser, practicar el arte de la civilidad y ser partícipes de la construcción de sociedad de manera pacífica, empleando los sentidos como fuente de cercanía al otro individuo, permitiéndose escuchar no solo lo que pueden expresar las demás personas, sino los silencios que habitan cada particularidad.

\section{Referencias}

Aguilar, L. A. (2003). Conversar para aprender. Gadamer y la educación. Sinéctica. Revista Electrónica de Educación, 23, 11-18. https://sinectica.iteso.mx/index.php/SINECTICA/ article/view/294/287

Bárcena, F. y Mèlich, J.-C. (2014). La educación como acontecimiento ético: Natalidad, narración y hospitalidad ( $2^{\mathrm{a}}$ ed.). Miño y Dávila Editores.

Barquero, A. R. (2014). La mirada del docente sobre la promoción de la convivencia entre las familias de su estudiantado. Revista actualidades Investigativas en Educación, 14(3), 1-24. 10.15517/AIE.V14I3.16098

Castoriadis, C. (1983). La institución imaginaria de la sociedad (Vol.1: Marxismo y teoría revolucionaria). Tusquets Editores.

Castoriadis, C. (1989). La institución imaginaria de la sociedad (Vol. 2: El imaginario social y la institución). Tusquets Editores.

Castoriadis, C. (1997). Ontología de la creación. Ensayo y error.

Castoriadis, C. (2013). La institución imaginaria de la sociedad (Vol.1: Marxismo y teoría revolucionaria). Tusquets Editores.

Cohen, H. (2004). El prójimo. Anthropos. 
http://doi.org/10.15359/ree.24-2.5

ROR: https://ror.org/01t466c14 Universidad Nacional, Costa Rica

http://www.una.ac.cr/educare

educare@una.cr

Dávalos, L. (2002). La escuela, un punto de encuentro. Revista electrónica Sinéctica, 20, 85-89. http://www.redalyc.org/articulo.oa?id=99817898014

Derrida, J. (1998). Políticas de amistad seguido de El oído de Heidegger. Trotto

Duarte, J. (2005). Comunicación en la convivencia escolar en la ciudad de Medellín. Estudios Pedagógicos, 31(1), 137-165. https://doi.org/10.4067/S0718-07052005000100008

Foucault, M. (2002). Vigilar y castigar: Nacimiento de la prisión. Siglo XXI.

Freire, P. (1985). La naturaleza política de la educación: Cultura, poder y liberación. Paidós.

Fuentes, A. (2012). Significación de la mediación y la cooperación entre pares en una experiencia de intervención para la convivencia escolar (tesis pregrado). Universidad de Chile, Santiago de Chile. http://repositorio.uchile.cl/handle/2250/116466

García-Pujadas, M. I., Pérez-Almaguer, R. y Hernández-Batista, R. (2013). Convivencia escolar en secundaria básica. Ciencias Holguín, 19(3), 1-11. http://www.redalyc.org/ pdf/1815/181528709007.pdf

Gijón, M. y Puig, J. M. (2010). Encuentros y convivencia escolar. Educação, 35(3), 367-379. http:// www.redalyc.org/articulo.oa?id=117116968002

Jaramillo Ocampo, D. A. y Murcia Peña, N. (2014). Hacia una pedagogía del encuentro: Apuestas por la relación cuerpo-alteridad en educación. Revista de Investigaciones UCM, 14(24), 142149. http://dx.doi.org/10.22383/ri.v14i2.28

Jaramillo Ocampo, D. A. y Orozco Vallejo, M. (2015). ¿Hablar del otro o hablar con el otro en educación? Revista Latinoamericana de Estudios Educativos, 11(2), 47-68. https://www. redalyc.org/articulo.oa?id=134146842003

Leiva, J.J. (2010). Educación intercultural y convivencia desde la perspectiva docente. Profesorado. Revista de Currículum y Formación de Profesorado, 14(3), 251-274. http://www.redalyc.org/ articulo.oa?id=56715702017

Levinas, E. (1977). Totalidad e infinito. Ensayo sobre la exterioridad. Ediciones Sígueme.

Levinas, E. (2009). Humanismo del otro hombre. Siglo XXI.

Levinas, E. (2015). Ética e infinito. Machado libros.

Méndez, C. A. y Mesa, Á. M. (2015). Exploración etnográfica de las prácticas de convivencia: Una experiencia de investigación-acción en la IED Ciudad de Villavicencio. Revista Aletheia, 7(1), 88-103. https://doi.org/10.11600/21450366.7.1aletheia.88.103 
http://doi.org/10.15359/ree.24-2.5

ROR: https://ror.org/01t466c14 Universidad Nacional, Costa Rica

Murcia, N. (2011). Imaginarios sociales: Preludios sobre universidad. Imaginario, imaginación, representación y simbólico: complementariedad y operacionalización de un diseño. EAE.

Murcia, N. (2012). La escuela como imaginario social: Apuntes para una escuela dinámica. Magistro, 6(12), 53-70. https://dialnet.unirioja.es/servlet/articulo?codigo $=4323068$

Murcia, N. y Jaramillo, L. G. (2008). Investigación cualitativa. La complementariedad. Una guía para abordar estudios sociales (2a ed.). Editorial Kinesis.

Ochoa, A. y Diez-Martínez, E. (2013). El reglamento escolar como eje de análisis de la convivencia en la escuela. Ensaio: Avaliação e Políticas Públicas em Educação, 21(81), 667-684. https:// doi.org/10.1590/S0104-40362013000400003

Perales, C., Bazdresch, J. M. Á. y Arias, E. (2013). La convivencia escolar desde la perspectiva de los estudiantes. Revista Iberoamericana De Evaluación Educativa, 6(2), 147-165.

Rodríguez, A. R. y González, M. A. (2015). Cultura organizacional de la diversidad expresada en la convivencia escolar y el desempeño académico (Tesis de grado). Universidad Católica de Manizales, Colombia. http://repositorio.ucm.edu.co:8080/ jspui/bitstream/handle/10839/1050/Ana\%20Rosaura\%20Rodriguez\%200rtiz. pdf? sequence $=1$ \&isAllowed $=y$

Sandoval, M. (2014). Convivencia y clima escolar: Claves de la gestión del conocimiento. Última década, 22(41), 153-178. https://doi.org/10.4067/S0718-22362014000200007

Skliar, C. (2008). El cuidado del otro. Argentina: Ministerio de Educación y Tecnología. http:// cosechador.siu.edu.ar/bdu3/Record/BNMBDIG--000171321

Viveros, É. y Vergara, C. E. (2014). Aproximación a la noción de encuentro en Emmanuel Lévinas. Revista Virtual Universidad Católica del Norte, 41, 61-69. 